\title{
Probiotics for Human and Poultry Use in the Control of Gastrointestinal Disease: A Review of Real-World Experiences
}

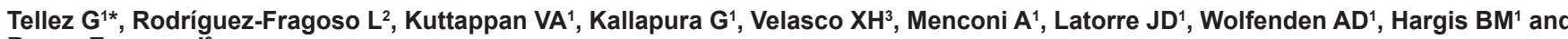
Reyes-Esparza $\mathrm{j}^{2}$

${ }^{1}$ Department of Poultry Science, University of Arkansas Fayetteville, AR 72701, USA

${ }^{2}$ Facultad de Farmacia, Universidad Autonoma del Estado de Morelos Cuernavaca, Morelos, 62210, Mexico

${ }^{3}$ Facultad de Medicina Veterinaria y Zootecnia, Universidad Nacional Autonoma de Mexico, Mexico

\begin{abstract}
Over a century ago Eli Metchnikoff proposed the revolutionary idea to consume viable bacteria to promote health by modulating the intestinal microflora. The idea is more applicable now than ever, since bacterial antimicrobial resistance has become a serious worldwide problem both in medical and agricultural fields. The interest in digestive physiology and the microbiome has generated data whereby well being of all living organisms with a digestive tract can be enhanced and the risk of disease reduced. Given the recent international legislation and domestic consumer pressures to withdraw growth-promoting antibiotics and limit antibiotics available for treatment of bacterial infections, probiotics can offer alternative options. Probiotics are live microorganisms that, when administered in adequate amounts, confer a health benefit on the host. Current indications are that mechanism of action involves a number of possibilities like rapid activation of innate host immune responses, assisting in the digestion of food materials etc. In this review, we focused on applying probiotic concept to alleviate chronic constipation and idiopathic diarrhea in humans or for specific pathogen reduction and improvement of GIT diseases in poultry. Based on this review, it is clear that the probiotic concept can be further explored to impact various areas of health and well being in both humans and animals.
\end{abstract}

Keywords: Probiotics; Lactic acid bacteria (LAB); Salmonella; Constipation; Enteritis

\section{Introduction}

Enteric problems and their treatment are of great concern both in humans and animals. The diarrhea caused as a result of cancer treatments in humans is a very good example. The chemotherapy induced is associated with increased morbidity and mortality, increased treatment costs, and limitations related to the ability to deliver full doses of chemotherapy [1]. In cases where chemotherapy associated diarrhea occurs, it may be necessary to discontinue or modify drug treatment until the diarrhea ceases [1]. Both chemotherapeutic agents and radiation can directly injure rapidly proliferating enterocytes in the enteric mucosa, while several chemotherapeutic agents also have direct effects on the intestinal microflora, frequently leading to diarrhea sometimes hemorrhagic, malabsorption and bacterial translocation [2]. Radiotherapy and chemotherapy treatments also depress immune function, increasing the likelihood of systemic disease [3]. Consequently, cancer patients undergoing chemotherapy or radiation therapy are often treated with high doses of broad spectrum antibiotics in an attempt to reduce such systemic disease. A common and unfortunate sequelae to this treatment is disruption of beneficial enteric microflora, allowing colonization by opportunistic pathogens such as Clostridium difficile, which frequently causes severe diarrhea and sometimes death $[1,4]$. Similarly, acute infectious diarrhea and chronic constipation are also two other enteric disturbances seen in humans. Meanwhile, in case of food animals, the occurrence of enteric disease can lead to huge economic loss. Salmonellosis is a highly contagious food borne pathogen with important economic repercussions in commercial poultry $[5,6]$. The use of antibiotics can be an effective way to control these types of infections, however, the use of antibiotic in food animals and the concern over the spread of antibiotic resistance genes is gaining global attention. The use of antibiotics is already banned in Europe since January 2006 [7]. The enteric complications in humans, impending ban of antibiotics in animal feed, the failure to identify new antibiotics and the inherent problems with developing new vaccines make a compelling case for developing alternative prophylactics. One such alternative approach involves the use of probiotics or beneficial bacterial cultures $[6,8,9]$.

Probiotics are defined as live microorganisms that, when administered in adequate amounts, confer a health benefit on the host. The administration of probiotics as part of the daily dietary intake can reduce the incidence and severity of acute and chronic enteric infection, facilitate prevention and reduced recurrence of certain cancers, and lower the incidence of several atopic conditions $[10,11]$. The field of probiosis has emerged as a new science with applications in farming and aquaculture as alternatives to antibiotics as well as prophylactics in humans $[12,13]$. Probiotics are being developed commercially for both human uses, primarily as novel foods or dietary supplements, and in animal feeds, poultry and aquaculture, for the prevention of gastrointestinal infections.

Probiosis, although not a new concept, has only recently begun to receive an increasing level of scientific interest. Probiotics as a viable alternative to antibiotics is an important venture. For this reason the development of new probiotic products that could be licensed for food animal use is receiving considerable interest [9-11]. Probiotics for

*Corresponding author: Guillermo Tellez, POSC 0-114, Department of Poultry Science, University of Arkansas, Fayetteville, AR 72701, USA, Fax: 479-575-8490 E-mail: gtellez@uark.edu

Received April 17 2013; Accepted May 27, 2013; Published May 30, 2013

Citation: Tellez G, Rodríguez-Fragoso L, Kuttappan VA, Kallapura G, Velasco XH et al. (2013) Probiotics for Human and Poultry Use in the Control of Gastrointestina Disease: A Review of Real-World Experiences. Altern Integ Med 2: 118. doi:10.4172/2327-5162.1000118

Copyright: (c) 2013 Tellez G, et al. This is an open-access article distributed unde the terms of the Creative Commons Attribution License, which permits unrestricted use, distribution, and reproduction in any medium, provided the original author and source are credited. 
Citation: Tellez G, Rodríguez-Fragoso L, Kuttappan VA, Kallapura G, Velasco XH, et al. (2013) Probiotics for Human and Poultry Use in the Control of Gastrointestinal Disease: A Review of Real-World Experiences. Altern Integ Med 2: 118. doi:10.4172/2327-5162.1000118

human use, on the other hand, are subjected to minimal restrictions at least as novel foods or as dietary supplements and come in many different forms. In supermarkets, they are often sold as dairy-type products containing live bacteria and in health food shops as capsules or tablets composed of lyophilized preparations of bacteria which promote a healthy gut. Currently, there is no universal class of probiotic bacterium. The commonly used probiotic bacterial cultures include lactic acid bacteria and Bacillus sp. considered as alternatives to antibiotics that are used in both human and animal production industry $[8,9,14-16]$. These bacteria are found normally in the gastrointestinal tract (GIT) of humans and animals and there is the vague notion that the use of indigenous or commensal microorganisms is somehow restoring the natural microflora to the gut. The present review is exploring the effect of probiotic, in both humans and animals, with respect to certain enteric disease conditions.

\section{Mechanism of Action of Probiotics}

The GIT contains a microenvironment of bacteria that influences the host in many ways. Colonization begins at birth and is followed by progressive assembly of a complex and dynamic microbial society regulated by elaborate and combinatorial microbial-microbial and host-microbial interactions $[17,18]$. A delicate balance exists regarding the interaction between intestinal microbiota interact with host tissues to determine gut physiological function under normal conditions. The fragile composition of the gut microflora can be affected by various factors such as age, diet, environment, stress and medication $[18,19]$. The factors that perturb this equilibrium, such as marked dietary changes, infections or antibiotic treatment, will promote gut dysfunction $[20,21]$. Primary motility disturbances can induce changes in the intestinal bacterial content and thereby further worsen intestinal physiology [17]. A range of host functions has revealed to be affected by indigenous microbial communities. For example, microflora can metabolize several nutrients that the host cannot digest and converts these to end products, a process which has a direct impact on digestive physiology [22-24]. In addition, the microbiota directs the assembly of the gut-associated lymphoid tissue [25], helps educate the immune system [26], modulates proliferation and differentiation of its epithelial lineages [18], regulates angiogenesis [4], modifies the activity of the enteric nervous system [22] and plays a key role in extracting and processing nutrients consumed in the diet [27]. Despite these important effects, the mechanisms by which the gut microbial community influences host biology remain almost entirely unknown [28]. Amongst the many benefits associated with the consumption of probiotics, modulation of the immune system has received considerable attention [26]. Numerous researchers have reported the ability of live bacterial cultures to also reduce colonization of opportunistic microorganisms in the gastrointestinal tract [8,29-31]. Balanced gastrointestinal microflora and immune-stimulation or regulation of cell mediated or humoral immunity are major functional effects attributed to the consumption of probiotics [18,26,32-36]. However, several animal and human studies have provided unequivocal evidence that specific strains of probiotics are able to stimulate multiple aspects of innate immunity $[3,8,20,37$ 40]. The importance of the intestinal microflora composition in physiological and pathophysiological processes in the GIT, is becoming more evident and has led to new possibilities for prevention and therapy of diseases $[4,18,41]$. There is a growing interest in probiotics as a safe way of changing the intestinal bacterial flora. It is possible to increase the proportion of Lactic acid bacteria (LAB) and Bacillus $s p$. in the gastrointestinal microflora by consumption of probiotics or by oral administration of specific non-digestible substrates, such as oligofructose, termed as prebiotics [42]. LAB and Bacillus sp. spores based probiotics are reported to have the potential to ameliorate several gastroenteric conditions, especially when the intestinal flora has been disturbed $[7,17,43]$.

\section{Effect of Probiotics in Certain GIT Diseases}

\section{Chemotherapy induced diarrhea}

Oral chemotherapy using anticancerous drugs can destroy the normal microflora in the GIT, leading to diarrhea which is difficult to control. Recently, El-Atti et al. reported a case study in which they used LAB culture to treat chemotherapy induced diarrhea in a cancer patient [44]. The authors reported the probiotic culture reduced the severity and frequency of diarrhea from day 1 administration. However, the patient reported that the diarrhea will relapse whenever she stops taking probiotics. From this report, the authors suggested that the adjuvant administration of probiotics along with chemotherapy can reduce the occurrence of chemotherapy induced diarrhea. Several studies have shown that either live vegetative cells or endospores of some Bacillus isolates can prevent colon carcinogenesis [45] or discharge antimicrobial substances against Gram-positive bacteria, such as Staphylococcus aureus, Enterococcus faecium, and Clostridium difficile [46]. This again suggests that Bacillus spores based probiotics can also be a potential candidate to be used an effective probiotic for the chemotherapy induced diarrhea.

\section{Acute infectious diarrhea}

Acute infectious gastroenteritis remains the most common cause of diarrhea worldwide and is a leading cause of death in childhood. This disorder is also a source of anxiety to families of affected children, representing a heavy economic burden for families and for society as a whole [47]. Despite improvements in public health and economic wealth, the incidence of intestinal infections remains high in the developed world and continues to be an important clinical problem with relevant morbidity [48]. The morbidity of acute infectious diarrhea includes complications such as dehydration or electrolyte imbalance. Another issue is the bacterial antimicrobial resistance in both the medical and agricultural fields has become a serious problem worldwide [49]. Antibiotic resistant strains of bacteria are an increasing threat to animal and human health, with resistance mechanisms having been identified and described for all known antimicrobials currently available for clinical use [49]. Because of this problem, there is a need to evaluate potential antibiotic alternatives to improve disease resistance. The use of certain $\mathrm{LAB}$ as probiotics have been reported to be effective in reducing the severity and duration of acute diarrhea: Lactobacillus rhamnosus formerly "Lactobacillus casei strain GG" or "Lactobacillus GG", L. plantarum, several strains of Bifidobacteria spp., Enterococcus faecium SF68, and preparations containing a mix of strains $[8,16,27,48,50]$.

In unpublished results from the author's laboratories, a prospective open controlled trial in a primary care center in two rural towns in Mexico, 200 children aged 10 to 12 years consulting for acute diarrhea were selected where the primary outcome measure was total duration of diarrhea and the number of bowel movements 24 hours after treatment and their consistency. Children were assigned to receive oral rehydratation solution alone, a probiotic mixture containing eleven strains of LAB, antibiotics or the combination of antibiotics plus the probiotic. Safety and tolerability of the probiotics were the secondary outcomes. Patients were allocated to each antibiotics group when they had fever, mucous stools, or tenesmus. The average of bowel movements 
Citation: Tellez G, Rodríguez-Fragoso L, Kuttappan VA, Kallapura G, Velasco XH, et al. (2013) Probiotics for Human and Poultry Use in the Control of Gastrointestinal Disease: A Review of Real-World Experiences. Altern Integ Med 2: 118. doi:10.4172/2327-5162.1000118

in the $24 \mathrm{~h}$ after beginning the treatment was smaller $(\mathrm{p}<0.01)$ in children who received probiotic and probiotic plus antibiotics treatment. In stool consistency there were not subjective differences between groups after treatment, however, subjective differences were observed between same treatment group before and after the treatment. There were no adverse events in the groups that receive probiotics neither antibiotics nor rehydratation. These preliminary and unpublished results suggest that the use of this probiotic culture is effective, safe and provides a good option for the treatment of acute infectious diarrhea in children. Similarly, a study conducted by Chen et al. observed that a probiotic with a mixture of Bacillus mesentericus, Enterococcus faecalis, and Clostridium butyricum reduced the harshness of diarrhea and duration of hospital stay in children with acute diarrhea mainly through the down-regulation of pro-inflammatory cytokines and up-regulation of anti-inflammatory cytokines [51].

\section{Chronic constipation}

Constipation is a common problem, and probiotics have been suggested to improve gastrointestinal symptoms in patients with chronic constipation [52-54]. Rodriguez-Fragoso et al. showed that a probiotic mixture containing eleven strains of LAB, increased the frequency of bowel movements in constipated patients and improved the consistency of their stools, suggesting that the use of this probiotic was effective, safe and provides beneficial effects on symptoms of chronic constipation [55]. The mechanisms for this are thought to be related to alterations in the intestinal microflora and production of short chain fatty acids SCFA, which biological and clinical properties have been extensively investigated $[22,23]$. SCFA stimulate the motility of the intestine probably through colonic motility by stimulating mucosal receptors connected to enteric and vagal nerves [56], colonic smooth muscle [57], and releasing gastrointestinal regulatory peptides that modulate intestinal motility such as polypeptide YY [58]. The motility of the GIT is important for absorption, transport, and clearance. Absorption is promoted by slow transit because of prolonged contact time, whereas clearance, by rapid transit [59]. Interestingly, recent studies have shown that gut transit is slow in the absence of the intestinal microflora [59$61]$.

However, there are contradicting reports about the effect of probiotics on chronic constipation. Some studies noted an increase in the amount of stool and reduced symptoms in adult patients with chronic constipation [53,62], while in other studies no improvement was observed [63]. Thus, the effect of probiotic ingestion on orofecal gut transit time appears to be dependent on the specific bacterial strains used and the population being studied.

\section{Probiotics in poultry research}

A number of researches have been conducting on preventing or reducing the occurrence of Salmonella infection in poultry $[11,29,30,64]$. Tellez et al. evaluated methods to select for individual enteric bacteria capable of inhibiting Salmonella growth in vitro and the ability of selected oxygen tolerant bacteria, in combination, to protect neonatal poults from Salmonella infection following challenge $[24,65,66]$. Concurrently, they also worked toward the isolation, selection, further evaluation and combination of LAB to control additional foodborne pathogens. Extensive laboratory and field research conducted with this defined LAB culture has demonstrated accelerated development of normal microflora in chickens and turkeys, providing increased resistance to Salmonella spp. infections [37,67-72]. Published experimental and commercial studies have shown that these selected probiotic organisms are able to reduce idiopathic diarrhea in commercial turkey brooding houses [73]. Large scale commercial trials indicated that appropriate administration of this probiotic mixture to turkeys and chickens increased performance and reduced costs of production $[69,74,75]$. These data have clearly demonstrated that selection of therapeutically efficacious probiotic cultures with marked performance benefits in poultry is possible, and that defined cultures can sometimes provide an attractive alternative to conventional antimicrobial therapy.

Tellez et al. [24] used molecular techniques to elucidate the action of $\mathrm{LAB}$ as a probiotics against Salmonellosis. Using a Salmonella challenge model, an effective LAB probiotic, administered 2 hours after Salmonella challenge, had no effect during the first 12 hours on increasing cecal colonization by this pathogen, although marked and rapid decreases were observed between 12 and 24 hours post-challenge [65,76]. Later, using the same model and microarray analysis of gut mRNA expression, gene expression differences in birds treated with a Lactobacillus-based probiotic were compared to saline treated birds. At $12 \mathrm{~h}$ post-probiotic treatment, 170 genes were significantly different $(\mathrm{p}<0.05)$, but by $24 \mathrm{~h}$ post treatment, the number of differentially regulated genes were 201 . Pathway analysis revealed that at both time points, genes associated with the $\mathrm{NF \kappa B}$ complex were significantly regulated, as well as genes involved in apoptosis. Probiotic-induced differential regulation of the genes GAS2 and CYR61 may result in increased apoptosis in the ceca of chicks. Because Salmonella is an intracellular pathogen, it was suggested that increased apoptosis may be a mechanism by which B11 reduces Salmonella infection [66].

In spite of the success showed by the development of the LAB probiotic for use in commercial poultry as described above, there is still an urgent need for commercial probiotics that are shelf-stable, cost-effective and feed-stable (tolerance to heat pelletization process) to increase compliance and widespread utilization. Among the large number of probiotic products in use today some are bacterial spore formers, mostly of the genus Bacillus. Both LAB and Bacillus have their own advantages and disadvantages. The LAB is found to be a better probiotic than Bacillus, but the latter one is more stable compared to the LAB mainly due to its spore forming ability. Used primarily in their spore form, some (though not all) have been shown to prevent selected gastrointestinal disorders and the diversity of species used and their applications are astonishing. While not all Bacillus spores are highly heat tolerant, some specific isolates are the toughest life form known on earth [77] and can be used under extreme heat conditions. These results provided evidence of colonization and antimicrobial activity of probiotic bacteria, thus, products containing Bacillus spores are used commercially as probiotics, and they offer potential advantages over the more common LAB products since they can be used as direct feed microbials [10,78-81]. There is scientific evidence suggesting that some but not all isolates of ingested B. subtilis spores can, in fact, germinate in the small intestine [79,82-84]. Together, these studies not only show that spores are not transient passengers in the gut, but they have an intimate interaction with the host cells or microflora that can enhance their potential probiotic effect. Several commercial spore-forming Bacillus cultures have been shown to reduce food borne pathogens $[79,81,85]$. However, cost issues associated with achieving necessary concentrations of spores in feed have greatly limited commercial acceptance $[10,86]$. While the majority of clear-cut research with regard to beneficial probiotic cultures has focused on LAB, as discussed above, a major question in several laboratories is whether or not selected sporeformer bacteria (genus Bacillus or related) can be as effective as the best known LAB cultures. Recently, one Bacillus subtilis spore isolate was as effective as a well-established LAB-based probiotic for Salmonella 
Citation: Tellez G, Rodríguez-Fragoso L, Kuttappan VA, Kallapura G, Velasco XH, et al. (2013) Probiotics for Human and Poultry Use in the Contro of Gastrointestinal Disease: A Review of Real-World Experiences. Altern Integ Med 2: 118. doi:10.4172/2327-5162.1000118

reduction in poultry $[87,85]$. Other isolates or combinations of isolates with increased potency and efficacy may be identified with continued research. Some of these environmental Bacillus isolates have been evaluated in vitro for antimicrobial activity against selected bacterial pathogens, heat stability, and the ability to grow to high numbers. Unpublished experimental evaluations by the author's laboratories have also confirmed improved body weight gain as well as Salmonella sp. or Clostridium perfringens reduction in commercial turkey and broiler operations when compared with medicated (nitarsone) or control non-medicated diets respectively. Indeed, preliminary data suggests that these isolates could be an effective alternative to antibiotic growth promoters for commercial poultry. Importantly, improved efficiency of amplification and sporulation is absolutely essential to gain widespread industry acceptance of a feed-based probiotic for ante mortem food borne pathogen intervention, as well as cost effectiveness. Recently, both vegetative growth and sporulation rates have been optimized, which may lead to new efficiencies for commercial amplification and manufacture of a cost-effective product at very high spore counts [88]. In order to select even more effective isolates, current research is focused on the mechanistic action of new Bacillus candidates. Preliminary studies indicate a potential mechanistic action of these new Bacillus candidates at least partially involve rapid activation of innate host immune mechanisms (system or responses) in chickens and turkeys (unpublished data). This data provides an exciting possibility for identification of vastly superior and more potent probiotics in the near future.

\section{Conclusion}

The interest in digestive physiology and the role of microorganisms has generated data whereby human and animal well being can be enhanced and the risk of disease reduced. Given the recent international legislation and domestic consumer pressures to withdraw growthpromoting antibiotics and limit antibiotics available for treatment of bacterial infections, probiotics can offer alternative options. New advances in the application of probiotics, are directed to produce significant changes in gut physiology and provide even higher levels of health in humans as well as increase performance parameters in poultry. Current research is still heavily biased toward gastrointestinal applications for probiotics, such as: chronic constipation [54,62,89]; diarrhea $[1,16,27,48]$; inflammatory bowel disease [27,90]; irritable bowel syndrome [9,91]; and food allergy [92], but the possibilities for impacting many areas of health are numerous. Research has shown that probiotics have potential for human health issues such as: vaginal candidiasis [17,38]; dental caries [93]; allergies [15,26]; autoimmune diseases [26,94,95]; urogenital infections [40]; atopic diseases [92,96]; rheumatoid arthritis [94,97]; and respiratory infections [50].

\section{References}

1. Mylonakis E, Ryan ET, Calderwood SB (2001) Clostridium difficile--Associated diarrhea: A review. Arch Intern Med 161: 525-533.

2. McGough C, Baldwin C, Frost G, Andreyev HJ (2004) Role of nutritional intervention in patients treated with radiotherapy for pelvic malignancy. $\mathrm{Br} \mathrm{J}$ Cancer 90: 2278-2287.

3. Helderman JH, Goral S (2002) Gastrointestinal complications of transplant immunosuppression. J Am Soc Nephrol 13: 277-287.

4. Sekirov I, Russell SL, Antunes LC, Finlay BB (2010) Gut microbiota in health and disease. Physiol Rev 90: 859-904.

5. Boyle EC, Bishop JL, GrassI GA, Finlay BB (2007) Salmonella: from pathogenesis to therapeutics. J Bacteriol 189: 1489-1495.

6. Carter AJ, Adams MR, Woodward MJ, La Ragione RM (2009) Control strategies for Salmonella colonization of poultry: The probiotic perspective. Food Sci Technol 5: 103-115.

7. Castanon $\mathrm{JI}$ (2007) History of the use of antibiotic as growth promoters in European poultry feeds. Poult Sci $86: 2466-2471$.

8. Alvarez-Olmos MI, Oberhelman RA (2001) Probiotic agents and infectious diseases: a modern perspective on a traditional therapy. Clin Infect Dis 32 1567-1576.

9. Rolfe RD (2000) The role of probiotic cultures in the control of gastrointestinal health. J Nutr 130: 396S-402S.

10. Hong HA, Duc le H, Cutting SM (2005) The use of bacterial spore formers as probiotics. FEMS Microbiol Rev 29: 813-835.

11. Sleator RD, Hill C (2008) New frontiers in probiotic research. Lett App Microbiol 46: 143-147.

12. Son VM, Chang CC, Wu MC, Guu YK, Chiu CH, et al. (2009) Dietary administration of the probiotic, Lactobacillus plantarum, enhanced the growth, innate immune responses, and disease resistance of the grouper Epinephelus coioides. Fish Shellfish Immunology 26: 691-698.

13. Verschuere L, Rombaut G, Sorgeloos P, Verstraete W (2000) Probiotic bacteria as biological control agents in aquaculture. Microbiol Mol Biol Rev 64: 655-671.

14. Canani RB, Cirillo P, Terrin G, Cesarano L, Spagnuolo MI, et al. (2007) Probiotics for treatment of acute diarrhoea in children: randomised clinical trial of five different preparations. BMJ 335: 340 .

15. Kirjavainen PV, Apostolou E, Salminen SJ, Isolauri E (1999) New aspects of probiotics--a novel approach in the management of food allergy. Allergy 54 909-915

16. de Roos NM, Katan MB (2000) Effects of probiotic bacteria on diarrhea, lipid metabolism, and carcinogenesis: a review of papers published between 1988 and 1998. Am J Clin Nutr 71: 405-411.

17. Blaser MJ (2006) Who are we? Indigenous microbes and the ecology of human diseases. EMBO Rep 7: 956-960.

18. Kau AL, Ahern PP, Griffin NW, Goodman AL, Gordon JI (2011) Human nutrition, the gut microbiome and the immune system. Nature 474: 327-336.

19. Kasper H (1998) Protection against gastrointestinal diseases--present facts and future developments. Int J Food Microbiol 41: 127-131.

20. Joint $F$ (2001) WHO Expert consultation on evaluation of health and nutritional properties of probiotics in food including powder milk with live lactic acid bacteria. Córdoba, Argentina. October: 1-4.

21. Fuller R (1991) Probiotics in human medicine. Gut 32: 439-442.

22. Kamath PS, Phillips SF (1988) Initiation of motility in canine ileum by short chain fatty acids and inhibition by pharmacological agents. Gut 29: 941-948.

23. Richardson A, Delbridge AT, Brown NJ, Rumsey RD, Read NW (1991) Short chain fatty acids in the terminal ileum accelerate stomach to caecum transit time in the rat. Gut 32: 266-269.

24. Tellez G, Higgins S, Donoghue A, Hargis B (2006) Digestive physiology and the role of microorganisms. J Appl Poult Res 15: 136-144.

25. Tsai YT, Cheng PC, Fan CK, Pan TM (2008) Time-dependent persistence of enhanced immune response by a potential probiotic strain Lactobacillus paracasei subsp. paracasei NTU 101. Int J Food Microbiol 128: 219-225.

26. Borchers AT, Selmi C, Meyers FJ, Keen CL, Gershwin ME (2009) Probiotics and immunity. J Gastroenterol 44: 26-46.

27. Teitelbaum JE, Walker WA (2002) Nutritional impact of pre- and probiotics as protective gastrointestinal organisms. Annu Rev Nutr 22: 107-138.

28. Sherman PM, Ossa JC, Johnson-Henry K (2009) Unraveling mechanisms of action of probiotics. Nutr Clin Pract 24: 10-14.

29. Applegate T, Klose V, Steiner T, Ganner A, Schatzmayr G (2010) Probiotics and phytogenics for poultry: Myth or reality? J Appl Poult Res 19: 194-210.

30. Flint J, Garner M (2009) Feeding beneficial bacteria: A natural solution for increasing efficiency and decreasing pathogens in animal agriculture. J Appl Poult Res 18: 367-378. 2009. 
Citation: Tellez G, Rodríguez-Fragoso L, Kuttappan VA, Kallapura G, Velasco XH, et al. (2013) Probiotics for Human and Poultry Use in the Contro of Gastrointestinal Disease: A Review of Real-World Experiences. Altern Integ Med 2: 118. doi:10.4172/2327-5162.1000118

31. Russell S, Grimes J (2009) The effect of a direct-fed microbial (Primalac) on turkey live performance. J Appl Poultr Res 18: 185-192.

32. Galdeano CM, de Leblanc Ade M, Carmuega E, Weill R, Perdigón G (2009) Mechanisms involved in the immunostimulation by probiotic fermented milk. J Dairy Res 76: 446-454.

33. Haghighi HR, Gong J, Gyles CL, Hayes MA, Sanei B, et al. (2005) Modulation of antibody-mediated immune response by probiotics in chickens. Clin Diagn Lab Immunol 12: 1387-1392.

34. Kimoto H, Mizumachi K, Okamoto T, Kurisaki J (2004) New Lactococcus strain with immunomodulatory activity: enhancement of Th1-type immune response. Microbiol Immunol 48: 75-82

35. MacDonald TT, Bell I (2010) Probiotics and the immune response to vaccines. Proc Nutr Soc 69: 442-446.

36. Taverniti V, Guglielmetti S (2011) The immunomodulatory properties of probiotic microorganisms beyond their viability (ghost probiotics: proposal of paraprobiotic concept). Genes Nutr 6: 261-274.

37. Farnell MB, Donoghue AM, de Los Santos FS, Blore PJ, Hargis BM, et al. (2006) Upregulation of oxidative burst and degranulation in chicken heterophils stimulated with probiotic bacteria. Poult Sci 85: 1900-1906.

38. Hawes SE, Hillier SL, Benedetti J, Stevens CE, Koutsky LA, et al. (1996) Hydrogen peroxide-producing lactobacilli and acquisition of vaginal infections. $\mathrm{J}$ Infect Dis 174: 1058-1063.

39. Huang MK, Choi YJ, Houde R, Lee JW, Lee B, et al. (2004) Effects of Lactobacilli and an acidophilic fungus on the production performance and immune responses in broiler chickens. Poult Sci 83: 788-795.

40. Reid G, Bruce AW (2003) Urogenital infections in women: can probiotics help? Postgrad Med J 79: 428-432.

41. Dominguez-Bello MG, Blaser MJ (2008) Do you have a probiotic in your future? Microbes Infect 10: 1072-1076.

42. Parracho H, McCartney AL, Gibson GR (2007) Probiotics and prebiotics in infant nutrition. Proc Nutr Soc 66: 405-411.

43. Kyriakis SC, Tsiloyiannis VK, Vlemmas J, Sarris K, Tsinas AC, et al. (1999) The effect of probiotic LSP 122 on the control of post-weaning diarrhoea syndrome of piglets. Res Vet Sci 67: 223-228.

44. Abd El-Atti S, Wasicek K, Mark S, Hegazi R (2009) Use of probiotics in the management of chemotherapy-induced diarrhea: a case study. JPEN J Parenter Enteral Nutr 33: 569-570.

45. Park E, Jeon GI, Park JS, Paik HD (2007) A probiotic strain of Bacillus polyfermenticus reduces $\mathrm{DMH}$ induced precancerous lesions in F344 male rat. Biol Pharm Bull 30: 569-574.

46. O'Mahony L, Feeney M, O'Halloran S, Murphy L, Kiely B, et al. (2001) Probiotic impact on microbial flora, inflammation and tumour development in IL-10 knockout mice. Aliment Pharmacol Ther 15: 1219-1225.

47. Bartick M, Reinhold A (2010) The burden of suboptimal breastfeeding in the United States: a pediatric cost analysis. Pediatrics 125: e1048-e1056.

48. Steffen R, Kollaritsch H, Fleischer K (2003) Travelers' diarrhea in the new millennium: consensus among experts from German-speaking countries. J Travel Med 10: 38-45.

49. Mathew AG, Cissell R, Liamthong S (2007) Antibiotic resistance in bacteria associated with food animals: a United States perspective of livestock production. Foodborne Pathog Dis 4: 115-133.

50. Arvola T, Laiho K, Torkkeli S, Mykkänen H, Salminen S, et al. (1999) Prophylactic Lactobacillus GG reduces antibiotic-associated diarrhea in children with respiratory infections: a randomized study. Pediatrics 104: e64.

51. Chen CC, Kong MS, Lai MW, Chao HC, Chang KW, et al. (2010) Probiotics have clinical, microbiologic, and immunologic efficacy in acute infectious diarrhea. Pediatr Infect Dis J 29: 135-138.

52. Bu LN, Chang MH, Ni YH, Chen HL, Cheng CC (2007) Lactobacillus casei rhamnosus Lcr35 in children with chronic constipation. Pediatr Int 49: 485-490.

53. Hamilton-Miller JM (2004) Probiotics and prebiotics in the elderly. Postgrad Med J 80: 447-451.

54. Locke GR 3rd, Pemberton JH, Phillips SF (2000) AGA technical review on constipation. American Gastroenterological Association. Gastroenterology 119: 1766-1778

55. Rodriguez-Fragoso L, Sandoval-Ocampo A, Corbalá-Nava M, Arjona-Canu CA, Gomez-Galicia DL, et al. (2012) Evaluation Regarding the Efficacy and Safety of a Probiotic Mixture in Healthy Volunteers with Evacuation Disorders. Food and Nutr 3: 117-122. 2012.

56. Dass NB, John AK, Bassil AK, Crumbley CW, Shehee WR, et al. (2007) The relationship between the effects of short-chain fatty acids on intestinal motility in vitro and GPR43 receptor activation. Neurogastroenterol Motil 19: 66-74.

57. Gibson GR, Roberfroid MB (1995) Dietary modulation of the human colonic microbiota: introducing the concept of prebiotics. J Nutr 125: 1401-1412.

58. Cherbut C, Ferrier L, Rozé C, Anini Y, Blottière H, et al. (1998) Short-chain fatty acids modify colonic motility through nerves and polypeptide $Y Y$ release in the rat. Am J Physiol 275: G1415-G1422.

59. Goossens D, Jonkers D, Stobberingh E, van den Bogaard A, Russel M, e al. (2003) Probiotics in gastroenterology: indications and future perspectives. Scand J Gastroenterol Suppl : 15-23.

60. Hammes WP, Hertel C (2002) Research approaches for pre-and probiotics: challenges and outlook. Food Res Int 35: 165-170.

61. Parvez S, Malik KA, Ah Kang S, Kim HY (2006) Probiotics and their fermented food products are beneficial for health. J Appl Microbiol 100: 1171-1185.

62. Fernández-Bañares $F(2006)$ Nutritional care of the patient with constipation Best Pract Res Clin Gastroenterol 20: 575-587.

63. Bekkali NL, Bongers ME, Van den Berg MM, Liem O, Benninga MA (2007) The role of a probiotics mixture in the treatment of childhood constipation: a pilot study. Nutr J 6: 17.

64. Menconi A, Wolfenden AD, Shivaramaiah S, Terraes JC, Urbano T, et al. (2011) Effect of lactic acid bacteria probiotic culture for the treatment of Salmonella enterica serovar Heidelberg in neonatal broiler chickens and turkey poults. Poult Sci 90: 561-565.

65. Higgins JP, Higgins SE, Vicente JL, Wolfenden AD, Tellez G, et al. (2007) Temporal effects of lactic acid bacteria probiotic culture on Salmonella in neonatal broilers. Poult Sci 86: 1662-1666.

66. Higgins SE, Wolfenden AD, Tellez G, Hargis BM, Porter TE (2011) Transcriptional profiling of cecal gene expression in probiotic- and Salmonellachallenged neonatal chicks. Poult Sci 90: 901-913.

67. Higgins JP, Andreatti Filho RL, Higgins SE, Wolfenden AD, Tellez G, et al (2008) Evaluation of Salmonella-lytic properties of bacteriophages isolated from commercial broiler houses. Avian Dis 52: 139-142.

68. Tellez G, Petrone VM, Escorcia M, Morishita TY, Cobb CW (2001) Evaluation of avian-specific probiotic and Salmonella enteritidis-, Salmonella typhimuriumand Salmonella heidelberg-specific antibodies on cecal colonization and organ invasion of Salmonella enteritidis in broilers. J Food Prot 64: 287-291.

69. Vicente J, Higgins S, Bielke L, Tellez G, Donoghue D (2007) Effect of probiotic culture candidates on Salmonella prevalence in commercial turkey houses. J Appl Poult Res 16: 471-476.

70. Vicente JL, Torres-Rodriguez A, Higgins SE, Pixley C, Tellez G, et al. (2008) Effect of a selected Lactobacillus spp.-based probiotic on Salmonella enterica serovar enteritidis-infected broiler chicks. Avian Dis 52: 143-146.

71. Wolfenden A, Pixley C, Higgins J, Higgins S, Vicente J, et al (2007) Evaluation of spray application of a Lactobacillus-based probiotic on Salmonella enteritidis colonization in broiler chickens. Int J Poult Sci 6: 493-496.

72. Wolfenden A, Pixley C, Vicente J, Aviña L, Hargis B, et al. (2007) Effect of an Organic Acid Product During Feed Withdrawal on Broiler Mortality, Shrinkage and Carcass Condemnation Following Transport to Processing. Int J Poult Sc 6: 497-500.

73. Higgins S, Torres-Rodriguez A, Vicente J, Sartor C, Pixley C, et al. (2005) Evaluation of intervention strategies for idiopathic diarrhea in commercial turkey brooding houses. J Appl Poult Res 14: 345-348.

74. Torres-Rodriguez A, Donoghue AM, Donoghue DJ, Barton JT, Tellez G, et al. (2007) Performance and condemnation rate analysis of commercial turkey flocks treated with a Lactobacillus spp.-based probiotic. Poult Sci 86: 444-446.

75. Torres-Rodriguez A, Higgins S, Vicente J, Wolfenden A, Gaona-Ramirez 
Citation: Tellez G, Rodríguez-Fragoso L, Kuttappan VA, Kallapura G, Velasco XH, et al. (2013) Probiotics for Human and Poultry Use in the Control of Gastrointestinal Disease: A Review of Real-World Experiences. Altern Integ Med 2: 118. doi:10.4172/2327-5162.1000118

G, et al. (2007) Effect of lactose as a prebiotic on turkey body weight under commercial conditions. J Appl Poult Res 16: 635-641.

76. Higgins JP, Higgins SE, Wolfenden AD, Henderson SN, Torres-Rodriguez A et al. (2010) Effect of lactic acid bacteria probiotic culture treatment timing on Salmonella Enteritidis in neonatal broilers. Poult Sci 89: 243-247.

77. Vreeland RH, Rosenzweig WD, Powers DW (2000) Isolation of a 250 millionyear-old halotolerant bacterium from a primary salt crystal. Nature 407: 897900.

78. Mazza P (1994) The use of Bacillus subtilis as an antidiarrhoeal microorganism. Boll Chim Farm 133: 3-18.

79. Hong HA, Huang JM, Khaneja R, Hiep LV, Urdaci MC, et al. (2008) The safety of Bacillus subtilis and Bacillus indicus as food probiotics. J Appl Microbiol 105: $510-520$

80. Kritas SK, Govaris A, Christodoulopoulos G, Burriel AR (2006) Effect of Bacillus licheniformis and Bacillus subtilis supplementation of ewe's feed on sheep milk production and young lamb mortality. J Vet Med A Physiol Pathol Clin Med 53: 170-173.

81. La Ragione RM, Woodward MJ (2003) Competitive exclusion by Bacillus subtilis spores of Salmonella enterica serotype Enteritidis and Clostridium perfringens in young chickens. Vet Microbiol 94: 245-256.

82. Duc le H, Hong HA, Barbosa TM, Henriques AO, Cutting SM (2004) Characterization of Bacillus probiotics available for human use. Appl Environ Microbiol 70: 2161-2171.

83. Hoa NT, Baccigalupi L, Huxham A, Smertenko A, Van PH, et al. (2000) Characterization of Bacillus species used for oral bacteriotherapy and bacterioprophylaxis of gastrointestinal disorders. Appl Environ Microbiol 66: 5241-5247.

84. Tam NK, Uyen NQ, Hong HA, Duc le H, Hoa TT, et al. (2006) The intestinal life cycle of Bacillus subtilis and close relatives. J Bacteriol 188: 2692-2700.

85. Wolfenden RE, Pumford NR, Morgan MJ, Shivaramaiah S, Wolfenden AD, et al. (2011) Evaluation of selected direct-fed microbial candidates on live performance and Salmonella reduction in commercial turkey brooding houses. Poult Sci 90: 2627-2631.
86. Coote JG (1974) Comparative studies on induction of sporulation and synthesis of inducible enzymes in Bacillus subtilis. J Bacteriol 120: 1102-1108.

87. Shivaramaiah S, Pumford NR, Morgan MJ, Wolfenden RE, Wolfenden AD, et al. (2011) Evaluation of Bacillus species as potential candidates for direct-fed microbials in commercial poultry. Poult Sci 90: 1574-1580.

88. Wolfenden R, Pumford N, Morgan M, Shivaramaiah S, Wolfenden A (2010) Evaluation of a screening and selection method for Bacillus isolates for use as effective direct-fed microbials in commercial poultry. Int J Poult Sci 9: 317-323.

89. Gallagher P, O'Mahony D (2009) Constipation in old age. Best Pract Res Clin Gastroenterol 23: 875-887.

90. Jonkers D, Stockbrügger R (2003) Probiotics and inflammatory bowel disease J R Soc Med 96: 167-171.

91. Quigley EM (2009) Probiotics and irritable bowel syndrome. Bioscience Microflora 28: 119-124.

92. Isolauri E, Kirjavainen PV, Salminen S (2002) Probiotics: a role in the treatment of intestinal infection and inflammation? Gut 50 Suppl 3: III54-III59.

93. Gross EL, Leys EJ, Gasparovich SR, Firestone ND, Schwartzbaum JA, et al (2010) Bacterial $16 \mathrm{~S}$ sequence analysis of severe caries in young permanent teeth. J Clin Microbiol 48: 4121-4128.

94. Bach JF (2005) Infections and autoimmune diseases. J Autoimmun 25: 74-80.

95. Sudo N, Sawamura S, Tanaka K, Aiba Y, Kubo C, et al. (1997) The requirement of intestinal bacterial flora for the development of an IgE production system fully susceptible to oral tolerance induction. J Immunol 159: 1739-1745.

96. Kalliomäki M, Salminen S, Arvilommi H, Kero P, Koskinen P, et al. (2001) Probiotics in primary prevention of atopic disease: a randomised placebocontrolled trial. Lancet 357: 1076-1079.

97. O'Dell JR, Haire CE, Erikson N, Drymalski W, Palmer W, et al. (1996) Treatment of rheumatoid arthritis with methotrexate alone, sulfasalazine and hydroxychloroquine, or a combination of all three medications. N Engl J Med 334: 1287-1291. 